\title{
MEMBANGUN INFRASTRUKTUR LAYANAN KEUANGAN DIGITAL PADA KAWASAN TERLUAR, TEPENCIL, TERISOLIR DAN TERTINGGAL DI PROVINSI KALIMANTAN BARAT
}

\author{
Prof. Dr. H. Arkanudin, M.Si ${ }^{\mathrm{a}}$ \\ Dr. Erdi, M.Si ${ }^{\mathrm{a}}$ \\ ${ }^{a}$ Departemen Antropologi Sosial Fakultas Ilmu Sosial dan Ilmu Politik, Universitas Tanjung Pura
}

\begin{abstract}
Abstrak
Ketika melaksanakan kegiatan penelitian di beberapa daerah tertinggal, daerah terbelakang, kawasan perbatasan dan kawasan hutan pedalaman di Kalimantan Barat tahun 2015 yang lalu, ternyata hampir seluruh daerah yang penulis kunjungi, mulai kawasan perbatasan di Kabupaten Sambas, Bengkayang, Sanggau, Sintang dan Kapuas Hulu, atau kawasan hutan pedalaman di Kabupaten Kapuas Hulu, kawasan Tertinggal dan Daerah Terisolir di Kabupaten Kayong Utara; Provinsi Kalimantan Barat telah mendapatkan layanan "keuangan dan perbankan" secara baik; tidak saja dalam transaksi manual tetapi juga secara online yang dilakukan oleh sebuah koperasi yang lebih dikenal dengan sebutan Credit Union (CU).

Seterusnya, ketika penulis masuk dalam ranah pelayanan keuangan oleh CU kepada anggotanya di beberapa daerah itu, pengurus CU di daerah yang penulis kunjungi di atas telah memastikan bahwa transaksi keuangan bagi seluruh anggota telah terlayani secara baik dan transparan. Dikatakan juga bahwa transaksi keuangan itu sesungguhnya dilakukan secara online karena terintegrasi dengan system layanan yang telah terbangun di beberapa kantor pusat CU. Sebaliknya, keadaan serupa belum mampu dilakukan oleh bank operasi di kawasan-kawasan tertinggal itu. Namun, kami tetap belum ingin membuat simpulan bahwa komitmen CU ternyata lebih hebat dan lebih kokoh dibanding komitmen Bank Indonesia (BI); apakan lagi dibanding dengan komitmen Bank Operasional (BO) yang lebih berorientasi pada bisnis.

Paper ini mencoba untuk melihat kendala dalam pembangunan infrastruktur layanan keuangan digital (LKD) di Kalimantan Barat yang semestinya dapat dilakukan oleh pemerintah dalam rangka memberikan layanan public kepada masyarakat yang selama ini belum tersentuh oleh layanan bank (underbanked) dan anggota masyarakat yang pelayanan perbankannya masih sangat terbatas (unbanked). mengingat layanan LKD adalah bagian integral dari layanan public yang telah menjadi komitmen dari pemerintah di negeri ini. Bukankan kehadiran pemerintah adalah untuk melindungi segenap bangsa Indonesia. Ketika jumlah mereka tidak dianggap cukup untuk diberikan pelayanan, apakah pemerintah dengan begitu saja meninggalkan mereka dan membiarkan hak-hak sebagai warga negara tidak terpenuhi di garis batas negeri? Kalau demikian adanya, maka kehadiran pemerintah di aras batas negeri patut dipertanyakan dan bahkan keberadaan mereka dianggap tidak penting dalam struktur pembentuk ekonomi politik di negeri ini.
\end{abstract}

Keywords: $\quad$ Transaksi Keuangan Online, Layanan Keuangan Digital, Infrastruktur Keuangan Digital, underbanked society dan unbanked society. 


\section{Latar Belakang}

Pemerintah negeri ini memang sedang berbenah. Berbagai paket kebijakan yang diwujudkan melalui program berbasis desa, mulai dari PLN dengan Program Elektrifikasi Desa dengan menambah layanan listrik desa dari posisi 73,95\% (2011) menuju posisi 85\% hingga tahun 2020 yang hingga kini belum kelar dan katanya terus diupayakan; disusul dengan program dari KOMINFO yang mengusung penyediaan layanan internet kecamatan melalui slogan "jangan biarkan yang tertinggal kian terkucil" kondisi fasilitasnya sedang kembang-kempis dimana mobil internet yang semestinya bergerak, terparkir di kantor kecamatan tanpa pelindung karena sudah tak dapat bergerak.

Jauh sebelumnya, program berbasis kebutuhan dasar warga seperti pendidikan dasar gratis dan kuliah gratis bagi kaum miskin dari KEMENDIKNAS juga terus bergulir dengan segala bentuk kekurangannya dan diharapkan mampu mencapai APK-PT usia 1923 tahun pada kisaran angka 75\% hingga tahun 2020. Demikian juga UPPKH (Unit Pelaksana Program Keluarga Harapan) dari Kementerian Koperasi dan UMKM masih terus berlanjut bagi mendorong rakyat kurang beruntung agar tidak tertinggal dalam pendidikan. Demikian juga layanan kesehatan dasar gratis yang terus berlanjut menyempurnakan paket dan bentuk layanannya dengan kondisi terkini melalui BPJS. Semua itu menunjukkan bahwa pemerintah ingin berbuat untuk warga mengikuti model citizen charter di Inggris seperti cerita [1].

Tak ketinggalan, Bank Indonesia (BI) melalui Peraturan Bank Indonesia (PBI) No. 16/8/PBI/2014 meluncurkan paket program Layanan Keuangan Digital (LKD) bagi masyarakat kurang beruntung, terutama mereka yang bermukim di kawasan tertinggal, terluar, terisolir, terbelakang dan termasuk juga bagi warga yang bermukim di kawasan perbatasan dan kawasan hutan konservasi. Namun, ternyata layanan LKD di Kalbar baru dalam tataran wacana atau konsep.

\section{Melirik Implementasi LKD pada CU di Kawasan TER Kalbar}

Ketika melihat fenomena layanan keuangan kepada masyarakat, penulis menemukan sebuah fakta yang luar biasa. Tidak disangka, sebut saja Credit Union (CU) ternyata sudah melakukan layanan keuangan digital ini kepada angota. Para para anggota CU yang penulis temui (sebutan anggota pada CU tidak disebut nasabah; meski perlakuan kepada anggota mirip atau dapat dipersamakan dengan nasabah) sudah sangat baik. Mereka dapat menarik uang dan pada beberapa mesin ATM (Anjungan Tunai Mandiri) dengan memanfaatkan keberadaan internet dan jaringan telepon seluler pada beberapa kantor CU di pedalaman dan juga dilengkapi dengan ATM Setor sehingga anggota CU dapat menyimpan uang atau menabung pada mesin ATM setor tersebut.

Ketika peneliti masuk dalam ranah pelayanan keuangan oleh CU kepada anggotanya di beberapa daerah TER di Provinsi Kalimantan Barat, pengurus CU di daerah yang penulis kunjungi mulai dari kawasan perbatasan di Kabupaten Sambas, Bengkayang, Sanggau, Sintang dan Kapuas Hulu, hingga kawasan hutan pedalaman di Kabupaten Kapuas Hulu, serta Tertinggal dan Daerah Terisolir di Kabupaten Kayong Utara; telah memastikan bahwa transaksi keuangan bagi seluru anggota telah terlayani secara baik dan transparan. Dikatakan juga bahwa transaksi keuangan itu sesungguhnya 
dilakukan secara online karena terintegrasi dengan system layanan yang telah terbangun di beberapa kantor pusat CU. Sebaliknya, keadaan serupa belum mampu dilakukan oleh bank operasi di kawasan-kawasan tertinggal itu. Meski sudah memiliki bukti kuat, kami belum boleh menyimpulan bahwa CU lebih hebat dibanding BI dan BO karena mereka sedang berusaha untuk berbuat seperti CU. Ketika nanti BI dan BO tidak mampu berbuat seperti CU, barulah proposisi yang tidak kami inginkan itu dapat dinyatakan secara tegas.

Layanan Keuangan Digital (LKD) tampaknya menjadi satu-satunya jalan untuk mendekatkan pelayanan perbankan pemerintah kepada masyarakat yang selama ini belum tersentuh oleh pelayanan bank (underbanked) dan juga kepada masyarakat yang pelayanan perbankannya masih sangat terbatas (unbanked); dan secara kebetulan pula mereka umumnya bermukim di wilayah tertinggal akibat keterbatasan akses transportasi. Ketika layanan dimaksud harus menunggu terbangunnya jalan darat, maka hasilnya akan seperti Program Elektrifikasi dimana, setelah merdeka selama lebih dari 70 tahun; rasio elektrifikasi di Kalbar baru mencapai 74,4\% atau sekitar 1.292 (dari 1.737 desa) dengan menyisakan sebanyak 445 desa belum tersentuh oleh jaringan listrik dari negara [2] .

Peluang masyarakat perdesaan untuk menjadi nasabah bank ternyata sangat tinggi karena mereka berada di wilayah yang kaya sumber daya. Ketiadaan layanan bank menjadikan mereka diklaim sebagai kelompok masyarakat yang tidak mengenal bank. Namun, dikotomi ini telah dibantah dan dibuktikan oleh CU dengan pelayanan yang sangat baik dan luar biasa. Ketika CU telah mampu memberikan layanan keuangan kepada masyarakat di wilayah tertinggal, terpencil dan terbelakang di hampir seluruh wilayah di Kalbar, maka sudah sepatutnya ada rasa malu dari BO yang dimotori BI bilamana mereka tidak mampu berbuat seperti CU. Ketika nanti LKD gagal dilaksanakan oleh BI melalui BO, barulah kami pantas untuk mengatakan bahwa baik BI maupun BO kalah hebat dari CU.

LKD ini diharapkan menjadi terobosan non konvensional untuk mendekatkan pelayanan kepada masyarakat dewasa yang disebut underbanked dan unbanked. Hingga 2014, posisi mereka berada pada kisaran $64,69 \%$ dari penduduk dewasa. Penduduk Indonesia tahun 2014 menurut BPS berjumlah 255.461.700 dan 51,40\% (131.307,314 jiwa) merupakan penduduk yang semestinya mendapat layanan perbankan. Namun, itu ternyata tidak terjadi karena layanan BO baru mampu menjangkau penduduk dewasa sebanyak 35,31\% dan masih menyisakan 64,69\% penduduk dewasa. Dari hitungan ini, berarti masih terdapat sebanyak 85 juta orang yang tergolong ke dalam underbanked dan unbanked; dan sebanyak 1,5 juta orang diantaranya, berada di Kalbar dan umumnya mereka bermukim di wilayah tertinggal (hasil hitungan penulis dari berbagai data statistik) yang saat ini telah dilayani oleh CU.

Kehadiran LKD, tidak saja dimaknai sebagai pemerataan dan keadilan yang tidak menimbulkan dikhotomi kota desa, tetapi juga sebagai wujud nyata pemberdayaan ekonomi daerah yang akan dilakukan oleh pemerintah melalui BI dan BO. Ketika Presiden Jokowi - JK memunculkan dan mewujudkan konsep Nawatica, khususnya cita ke-3: Membangun Indonesia dari pinggiran dengan memperkuat daerah-daerah dan desa dalam kerangka negara kesatuan [3] ; barulah masyarakat di kawasan TER dalam kontek layanan keuangan ini terpikirkan. Salah satu dari wujud program tersebut adalah 
terintegrasinya layanan perbankan dengan pengguna telepon selular melalui berbagai aplikasi transaksi keuangan.

Dalam kontek ini pula, salah satu cara yang dapat dilakukan BI adalah mendesain LKD yang terhubung dengan layanan telepon seluler (mobile phone) dan atau internet. Hanya LKD yang memungkinkan untuk menarik penduduk underbanked dan unbanked ke wilayah layanan BO agar keterbatasan akses transportasi tidak lagi menjadi kendala dalam melakukan aktivitas perbankan pada daerah tertinggal. Ketika program atau layanan ini belum dapat menjangkau seluruh kawasan TER, paling tidak dimulai dari kawasan yang paling memungkinkan untuk melaukan yang antara lain adalah kawasan perbatasan, meskipun masih tergolong tertinggal, tetapi kondisi infrastruktur transportasi dan sitem komunikasinya sudah lebih baik saat ini.

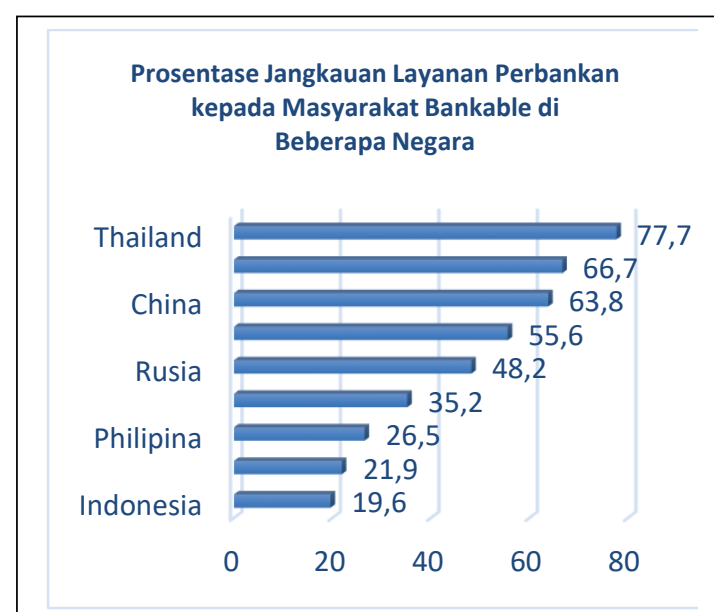

Sumber: WB, 2011

Berdasarkan data Bank Dunia tahun 2011, akses penduduk Indonesia terhadap bank masih tergolong rendah yakni hanya $19,6 \%$. Sedangkan negara-negara tetangga; diantaranya Malaysia 66,7\%, Philipina $26,5 \%$, Thailand $77,7 \%$, Vietnam $21,4 \%$, India $35,2 \%$, China 63,8\%, Rusia 48,2\%, dan Brazil 55,9\%. Akses penduduk pada layanan keuangan perbankan dapat dijadikan salah indikator kemajuan dan kesejahteraan suatu negara. Dengan data itu, Indonesia masih jauh tertinggal dibanding negara-negara sekelas dengan Indonesia.

\section{Darimana Memulai Layanan?}

Harus diakui bahwa beratnya medan geografis di Kalbar menyebabkan aksesbilitas pada teknologi informasi dan komunikasi termasuk layanan operator seluler menjadi terbatas pada daerah-daerah TER itu. Beberapa operator yang mengklaim dirinya sebagai operator dengan layanan sinyal terluas dan sinyal kencang ternyata harus tunduk pada bentang alam Kalbar. Pada tahun 2015, beberapa daerah yang tadinya tidak terlayani oleh seluler, telah dapat menikmati layanan telepon nirkabel dan sekaligus memungkinkan mengimplementasikan LKD. Tentu, implementasi LKD masih membutuhkan pendampingan dari BO hingga mereka dapat berjalan sendiri seperti yang telah dilakukan oleh CU selama ini pada unit-unit kerja baru mereka.

Dalam kontek mendekatkan layanan perbankan digital di wilayah yang tergolong "TER" ini, sebagai akademisi, kami sangat setuju jika rencana implementasi LKD harus direalisasikan paling lambat 2016. Agar implementasi LKD ini sukses, perlu didahului dengan survey pemetaan potensi di masing-masing wilayah kecamatan sasaran agar implementasi LKD berpeluang sukses dan sekaligus membantah proposisi (hipotesis) yang telah kami bangun dengan cerita layanan CU yang lebih baik dari layanan BI dan BO. 


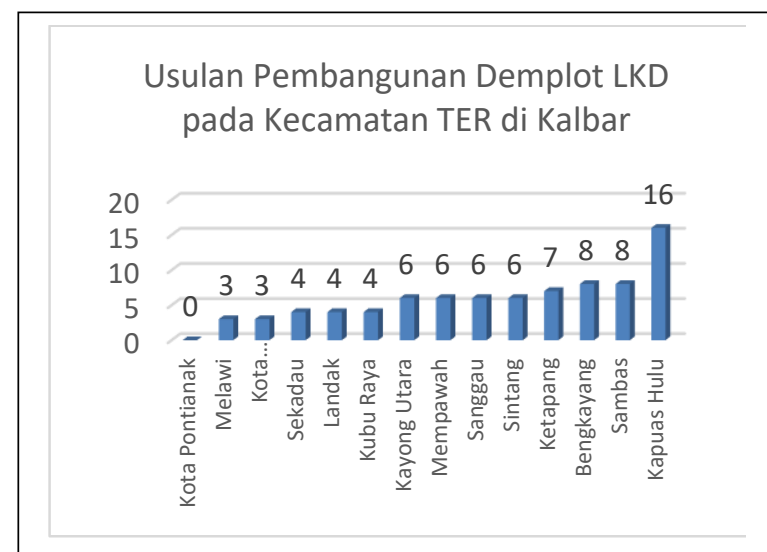

Sumber: Penulis, 2016
Dari komunikasi dengan pihak Bappeda se Kalimantan Barat, diperoleh gambaran bahwa wilayah kecamatan yang tergolong underbanked dan unbanked itu tersebar pada 81 dari 175 kecamatan se Kalbar. Wilayah underbanked dan unbanked dimaksud tidak termasuk Kota Pontianak. Untuk itu, bilamana BI Perwakilan Kalbar hendak memilih lokasi untuk implementasi LKD, direkomendasikan dilakukan pada 81 wilayah kecamatan di 12 Kabupaten dan 1 wilayah kota.

Persebaran daerah tersebut adalah 16 kec. di Kab. Kapuas Hulu, 8 kec. di Kab. Bengkayang, 4 kec. di Kab. Sekadau, 8 kec. di Kab. Sambas, 7 kec. di Kab. Ketapang, 3 kec. di KKU, 6 kec. di Kab. Landak, 4 kec. di KKR, 4 kec. di Kab. Mempawah, 5 kec. di Kab. Sanggau, 6 kec. di Kab. Sintang, dan 6 kec. di Kab. Melawi serta 3 wilayah kecamatan di Kota Singkawang. Diharapkan kehadiran LKD ini nanti dapat lebih mensejahterakan masyarakat di kawasan tertinggal di seluruh Kalbar. Semoga!

\section{Penutup}

Implementasi LKD dimaksudkan sebagai wujud dari upaya pemerintah untuk memberikan kesamaan hak dan perluasan pelayanan bagi masyarakat di bidang perbankan. Oleh karena itu, keberadaan sarana layanan sudah tidak dapat ditawar lagi. Implementasi Itu merupakan konsekwensi dari sebuah putusan public yang telah diputuskan oleh pemerintah melalui kebijakan. Namun, tidak semua kawasan dapat dilakukan penyediaan LKD sehingga pemerintah; melalui Bank Indonesia dapat memilih beberapa titik sebagai kawasan demontrasi atau uji coba.

Ketika dihubungkan dengan nawacita ketiga dari pemerintahan Jokowi - JK: Membangun Indonesia dari pinggiran dengan memperkuat daerah-daerah dan desa dalam kerangka negara kesatuan, maka daerah yang paling memungkinkan diantara 81 kecamatan yang membutuhkan LKD adalah kawasan perbatasan. Diharapkan, setiap kabupaten perbatasan ditetapkan 1 (satu) demplot; sehingga dibutuhkan 5 demprot LKD. Bilamana itu yang dipilih, maka implementasi LKD pada kawasan perbatasan itu akan ditempatkan di Kabupaten Sanggau, Kabupaten Sintang, Kabupaten Sambas, Kabupaten Kapuas Hulu dan Kabupaten Bengkayang. Implementasi LKD itu juga dimaksudkan agar public tidak berkesimpulan bahwa layanan CU adalah lebih baik dibanding layanan BO; yang bermakna pelemahan posisi strategis BI sebagai pemimpin bagi BO.

\section{Referensi}

[1] P. S. and P. W. Pattie, Charles, Citizenship in Britain: Values, Participation and Democracy. Cambridge: Cambridge University Press, 2004.

[2] Erdi, "Kebijakan Sapu Jagad Listrik Indonesia," Kolom Edukasi Harian Pontianak Post, Pontianak, 17-Apr-2016. 
[3] Bappenas RI, "Rencana Pembangunan Jangka Menengah Nasional 2015 - 2019," Jakarta, 2014. 